\title{
Receiving concrete with the superadsorbing component
}

\author{
Aleksander Buryanov ${ }^{1,}{ }^{*}$, Victoria Petropavlovskaya ${ }^{2}$, Tatiana Novichenkova ${ }^{2}$, and Kirill \\ Petropavlovskii ${ }^{2}$ \\ ${ }^{1}$ The Department of binders and concretes, Moscow State University of Civil Engineering, 26 \\ Yaroslavskoe sh., 129337 Moscow, Russia \\ ${ }^{2}$ Tver State Technical University, 22 Af. Nikitin, 170026 Tver, Russia
}

\begin{abstract}
Any period of high temperature in which special precautions need to be taken to ensure proper handling, placing, finishing, and curing of concrete. High winds, low relative humidity, and solar radiation all have major effects on concrete. Hot weather conditions can produce a rapid rate of evaporation of moisture from the surface of the concrete and accelerated setting time, among other problems. Generally, high relative humidity tends to reduce the effects of high temperature, because of hot and dry climate in the Iraq has been the addition of the gel to the mixture of concrete for keeping the water into the concrete during solidification and prevent cracks. Through the results, it showed an increase in the moisture content in the samples who containing a certain percentage of the gel in (728) days with the increase in the resistance ratio (strength of the concrete).
\end{abstract}

\section{Introduction}

While hot weather conditions are commonly encountered in summer, combinations of high temperatures, winds and low humidity could result in conditions leading to problems with concrete placement and finishing at any time [1]. Effect of hot weather conditions on the properties of concrete need the precautions that should be taken, particularly with flatwork, to minimize any potential adverse effects when placing concrete under these conditions $[2$, 3 , 4]. Heat resistant concrete, designed for industrial and construction, with prolonged exposure to high temperatures should be saved in the specified limits their physical and mechanical properties [5]. Heat resistant concrete manufactures cementitious (in which, where appropriate, introduce more active fine and mineral supplement), water (or other a mixing) and refractory aggregates $[6,7]$. Results of research and surveillance state test sites show that can reduce the water absorption of concrete up to $0.1-0.3 \%$ (by weight) and at the same time ensure its resistance of the surface layers (impregnation to a depth of $3-5 \mathrm{~mm}$ ) under dry and hot climate according of assessment to some researchers [8]. Hydration is an exothermic reaction, meaning it generates heat, and that reaction goes faster when the concrete is hot. So the main concern with the concrete's strength and set time isn't really the air temperature but the concrete temperature. When cement hydrates it sucks up water and

* Corresponding author: rga-service@mail.ru 
grows crystals around the aggregate particles. When it's hot and that reaction is rapid, the crystals grow quickly but don't have time to grow strong. Early strength will be higher but 28-day strength suffers. If the concrete is about $18^{\circ}$ hotter than normal (for example, $88^{\circ}$ instead of $70^{\circ}$ ), the ultimate compressive strength will be about $10 \%$ lower, in hot weather, as the cement sets up, slump decreases rapidly and more mixing water is needed. This can also contribute to lower strengths (as much as another 10\% lower), and in integrally colored concrete, can lead to variations in water content which can result in significant differences in concrete color between adjacent pours [2]. Another potential problem in hot weather is surface drying - although this one comes with a caveat. If the concrete is warm and the sun is shining and there is a hot dry wind, likely to get the concrete more drying and surface shrinkage, and, besides, may be: strength reduction, cracking, shrinkage cracks, and finishing difficulties [3].

\section{Main part}

There are many types of admixtures available for incorporation in concrete to achieve of a enhances certain properties or to achieve economy or both. Generally, admixtures affect shrinkage of the concrete to a varying degree depending on their formulation, their interaction with the cement, their interaction with other admixtures in the mix, and on the variations or adjustments they bring about in the proportions of the concrete mix. Adding the percentage of the mixture of Super Absorbent Polymers and Water holding inside for a specific period of time and thus compensate during the dry and hot climates, thereby reducing the drought and concrete cracks and similar applications [4].

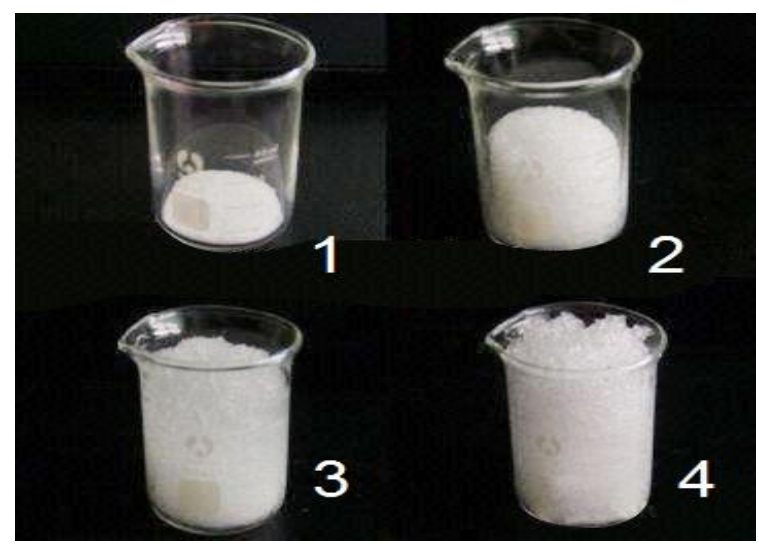

Fig. 1. Gel: (1) dry gel; (2) 5-8 sec after water added; (3) ready to add more water; (4) $30 \mathrm{sec}$ after adding more water.

Results showed what after 7 days a decrease in density of concrete with adding Gel happens monotonically. But after 28 days found a significant increase in the density ratio of the concrete when the amount of gel $1 \%$. Gel works in concrete most long as the best super adsorbing polymer for water during process of hardening of the concrete in case of this ratio (refer with: Fig. 2). 


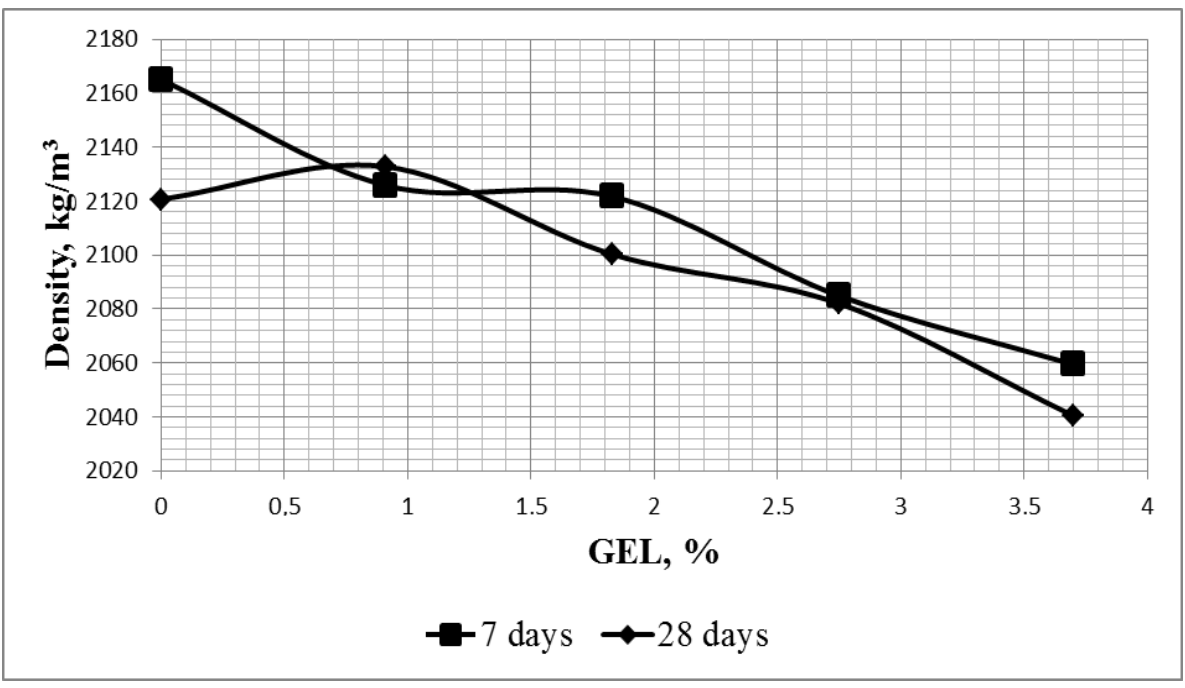

Fig. 2. Relationship between the proportion of Gel added to the concrete mixture with the average density of the concrete in $(7,28)$ days.

The component of Gel influences concrete strength. The received results of strength at the age of 28 days show that the optimum content of Gel corresponds by Gel $\sim 2 \%$ (refer with: Fig. 3). In case of optimum of Gel additions strength of concrete of $23.34 \mathrm{MPa}$ reaches. However concrete density depends on amount of additive a little (refer with: Fig. 2). Dynamics of change of strength from the content of additive is more brightly expressed for concrete at the age of 7 days.

The maximum strength corresponds to the water / solid relation -0.125 (refer with: Fig. 4).

It is caused by more active curing of a cement stone during this period. Processes of hydration proceed more actively. Therefore maintenance of the modes of humidity during the period up to 7 days is necessary. It will provide the high strength and fuller course of process of structurization.

The general density of system the solvation sheath on cement grains reduces a thickening. It can't but have an adverse effect on properties of cement stone and concrete. When curing such cement stone will be inclined to contraction. 


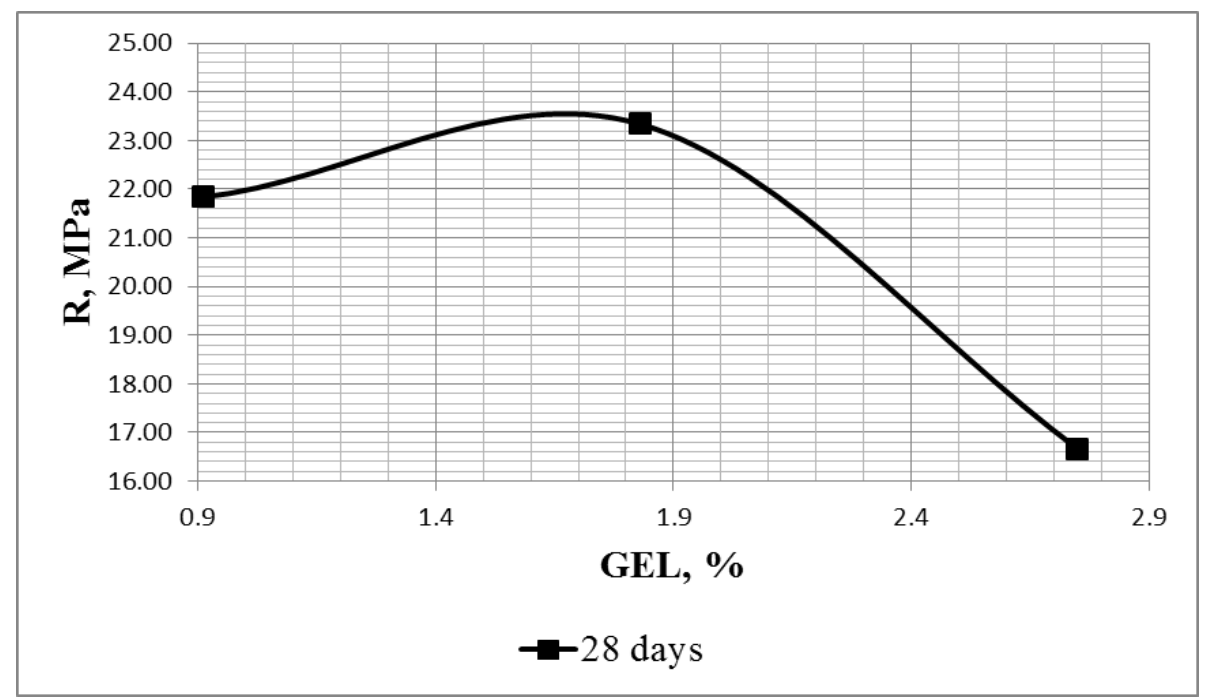

Fig. 3. Relationship between gel additions in the concrete mixture with the strength of the concrete (28 days).

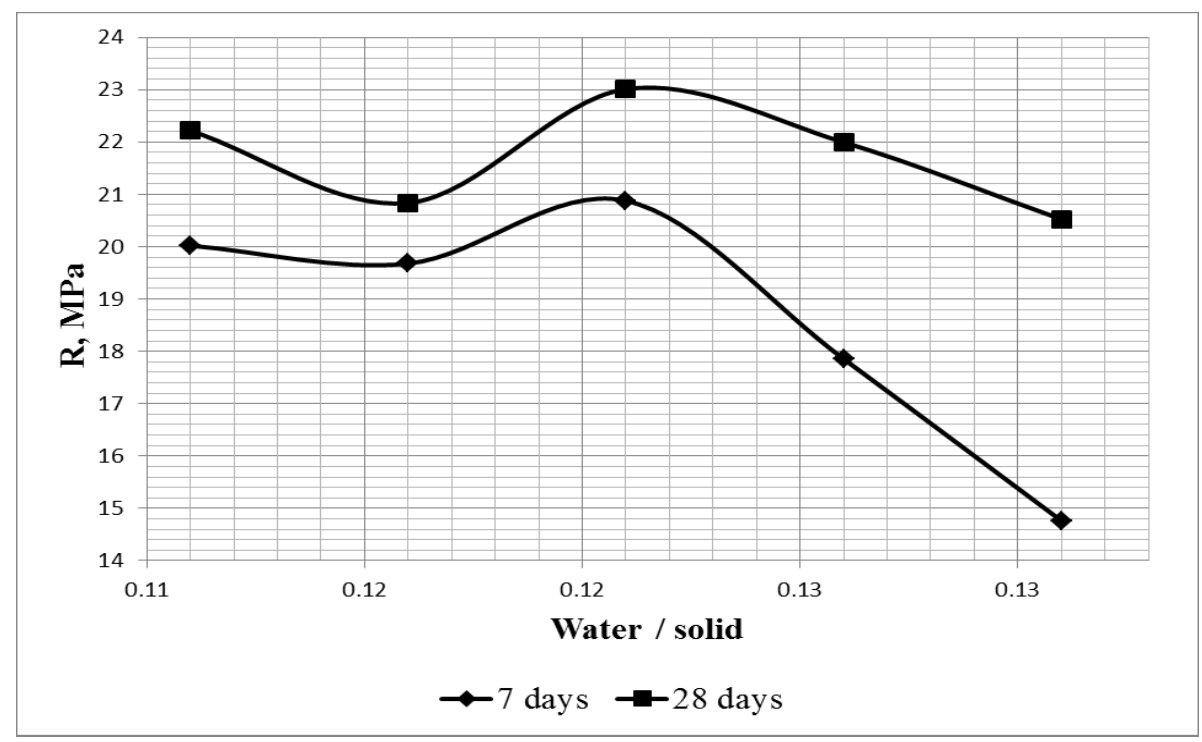

Fig. 4. Relationship between water/ solid relation in the concrete mixture with the strength of the concrete ( 7,28 days).

Types of hot concrete structure of concrete after 7 days of hardening (refer with: Fig. 5) and micro-structure after 28 days of hardening was shown (refer with: Fig. 6) through the micro-photo in micro-structure of mixture concrete penetration of Cotton and GEL inside parts of the concrete and connecting parts of the concrete which has contributed to increased strength of concrete and an increase in relative humidity. The additions (GEL, Cotton, Water) in the concrete mixture does not cause dryness concrete, formation cracks but it worked Super Absorbent Polymers and Water holding inside the mixture of concrete for a specific period of time and this led to increase in the efficiency of the work of concrete in conditions of a hot, dry climate. 
It is established that use of preliminary saturation leads to education in structure of concrete of the large time reducing its strength (refer with: Fig. 5). Use of the additive of GEL without her preliminary saturation by water more effectively. In concrete additional porosity, which reduces concrete strength, isn't formed (refer with: Fig. 6).

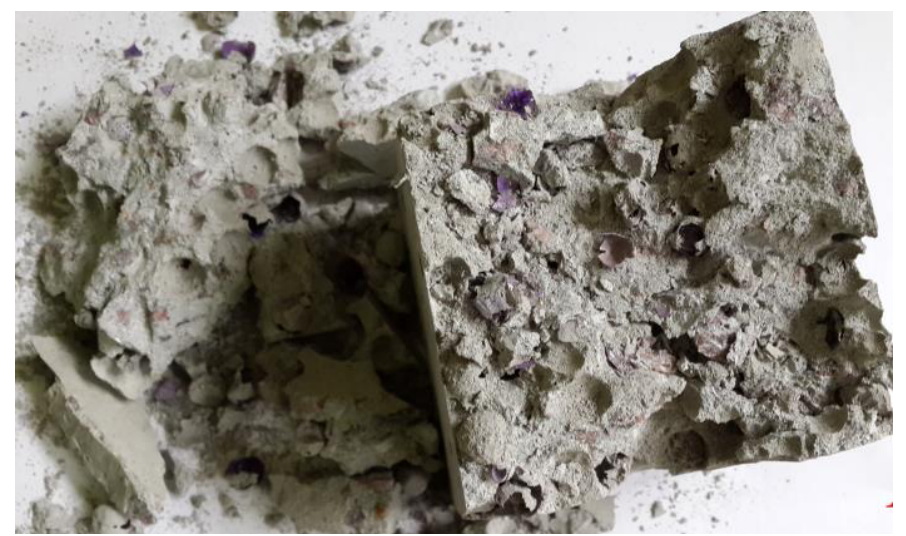

Fig. 5. Structure of concrete with GEL additions after test.

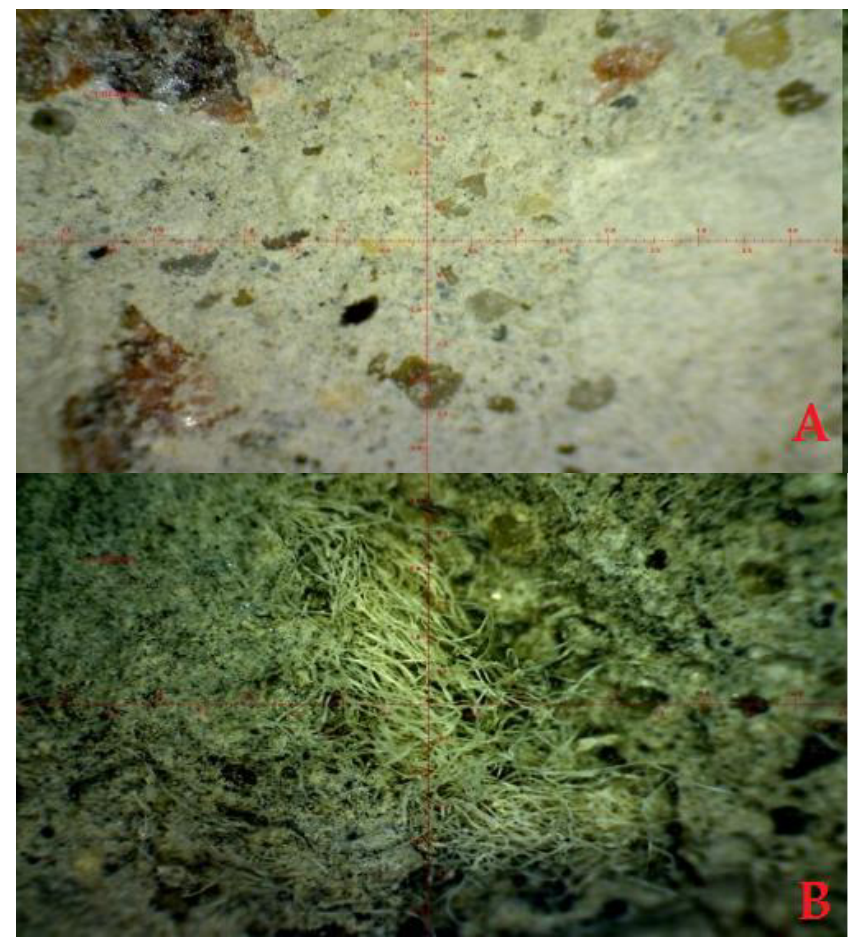

Fig. 6. Microstructure of concrete: (A) without gel; (B) with gel additions.

\section{Conclusions}

High strength of concrete through the addition of the Gel to the concrete mixture is reached, thereby increasing the work efficiency of the concrete under the hot, dry weather, such as 
Iraq's climate. The increase of the humidity of the concrete by addition of Gel leads to increasing water in the concrete for a longer period. So the efficiency of the work of concrete within the hot, dry climate is increasing.

\section{References}

1. AS 1379 Manufacture and supply of concrete Standards Australia (1997)

2. ACI Committee 305, Hot Weather Concreting ACI. Manual of Concrete Practice Part 2: Construction practices and inspection, pavements (American Concrete Institute, Farmington Hills, 1999)

3. V.V. Rusina, Construction materials, 12-13 (2013)

4. Buchholz and Graham, Modern Superabsorbent Polymer Technology (John Wiley \& Sons, 1998)

5. Information on http://www.amcol.com/fctbook/absor.htm

6. P.V. Smirnova, L.V. Morgun, Construction material, 96-97 (2013)

7. A.M. Scheinin, Cement concrete for road and airfield pavements (Transport, Moscow, 1991)

8. Material journee technical on roads in beton (Cemsuisse, Fribourg, 2005) 